\title{
Sickness absence rates across the NHS
}

Sickness rates among doctors were less than a third of rates across the NHS as a whole in 2016/17, data released by NHS Digital show

\section{Tom Moberly}

The BMJ

On average, hospital doctors were absent because of sickness on $1.3 \%$ of the days on which they were scheduled to work in 2016/17. Doctors in training had an average annual sickness rate of $1.1 \%$, and the average rate among consultants was $1.2 \%$. This compares with an average annual sickness absence rate of $4.2 \%$ for all NHS hospital staff, $4.5 \%$ for nurses, and $5.5 \%$ for ambulance workers.

Data from the Office for National Statistics (ONS) for 2016 recorded an absence rate across all workers in the health sector of $3.5 \%$. This compares with an average rate of $2.9 \%$ across the public sector and $1.7 \%$ in the private sector. In its analysis of these data, the ONS says, "It is possible that the exposure of health workers to infections and diseases contributes to their higher sickness absence rate."

The ONS data show that, across all UK workers, minor illnesses, such as coughs and colds, were the most common reason for sickness absence in 2016. These accounted for $25 \%$ of the total days lost. The next most common reasons were musculoskeletal problems, accounting for $22 \%$ of days lost.

Rates of sickness absence among NHS workers vary through the year, with lower rates in the summer and higher rates over the winter. Among doctors, absence rates are highest in December and January (an average of $1.3 \%$ in these months between 2010 and 2017) and lowest in August (an average of $1.0 \%$ between 2010 and 2017). 


\section{Figures}

Sickness absence rates among NHS staff and other workers

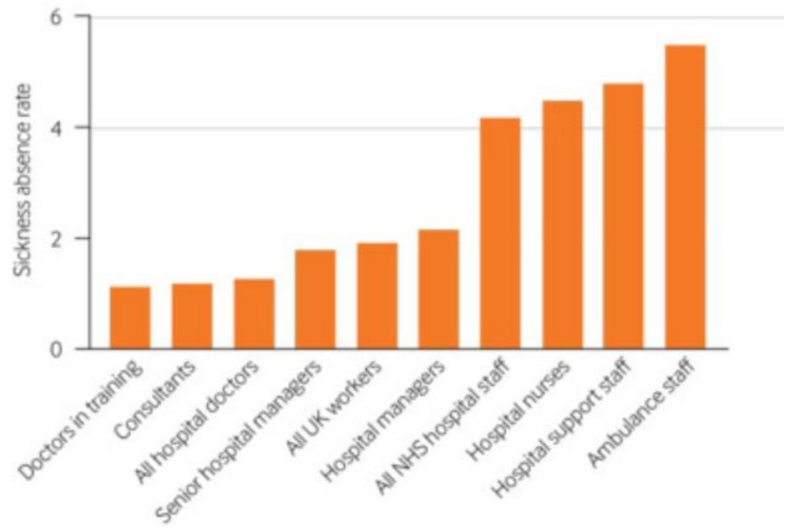

Percentage of sickness absences in 2016

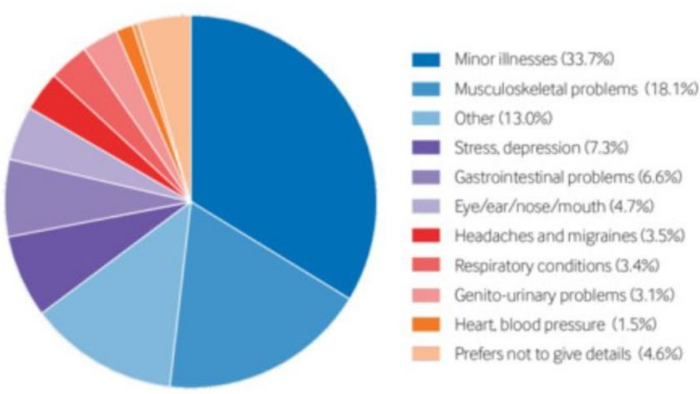

